\title{
Imagination and medical education
}

Donald Evans University of Otago, Dunedin, New Zealand

\begin{abstract}
Rival and apparently exclusive views have been canvassed about the instrumental use of the humanities in medical education. The novel is seen as offering exemplifications of moral principles on the one hand, whilst on the other such an approach is said to miss the essence of reading a novel by misrepresenting the engagment of the reader. The use of the humanities in medicine as a stimulus to reflective practice is presented as a preferable account which recognises that there is truth in each of the former views.

(f Med Ethics: Medical Humanities 2001;27:30-34)
\end{abstract}

"'You are too young to know how the world changes every day', said Mrs Creakle, 'and how the people in it pass away. But we all have to learn it David; some of us when we are young, some of us when we are old, some of us at all times of our lives.' I looked at her earnestly.

'When you came away from home at the end of the vacation,' said Mrs. Creakle, after a pause, 'were they all well?' After another pause, 'Was your Mama well?'

I trembled without distinctly knowing why, and still looked at her earnestly, making no attempt to answer.

'Because,' said she, 'I grieve to tell you that I hear this morning your Mama is very ill.'

A mist rose between Mrs Creakle and me, and her figure seemed to move in it for an instant. Then I felt the burning tears run down my face, and it was steady again.

'She's very dangerously ill,' she added.

I knew all now.

'She is dead.'

There was no need to tell me so. I had already broken out into a desolate cry, and felt an orphan in the wide world."'1

\section{Rival accounts of the role of the arts in medical education}

There is an ongoing debate about the usefulness of literature and the fine arts in medical education. The growth of the subdiscipline of medical humanities reflects a conviction that study of the arts can be beneficial in the practice of medicine. But there is dispute as to how this is possible. Two recent contributors to the discussion have presented rival accounts that are incompatible to the extent that one of them avowedly excludes the other as improper. One contributor holds that the various principles of good practice are exemplified in a nar- rative $^{2}$; whereas the other argues that reading a novel rather tells the reader something about herself and that in so doing might affect the manner in which that practitioner might approach her practice. $^{3}$

There is something valuable to be learned from each of these accounts.

In the case of the former it might be that a principle takes on a new vivacity for the practitioner as a result of her coming across it in a non-threatening context. Stories have traditionally been used in this way to bring home to readers a moral which needed reinforcement. Aesop's fables and the story told by Nathan the prophet to the scheming King David ${ }^{4}$ are telling examples. However, the latter view implies that without a personal engagement with the narrative a reading is at best shallow and at worst distorted and doctrinaire. According to this view we cannot predict what, if anything, the reader might learn from the narrative; apparently this lack of predictability undermines (or even defeats) the instrumental use of the narrative as a teaching tool. Further, what is learned might be as much a power for evil as for good.

It is certainly true that the former account's usefulness is tempered by the inescapable fact that simply trawling novels for exemplifications of preferred rules of behaviour can become a dead and stultifying activity. The novel might thus become a repository for data of various kinds rather than a compelling tale and any impact on the reader be lost. The distinction has been well made between these two kinds of reading in a discussion of the assertion: "When I read a poem or narrative with feeling, surely something goes on in me which does not go on when I merely skim the lines for information". ${ }^{5}$ It is not so much that the words or principles appear in a narrative that counts as the way in which they are read. A change of emphasis or intonation in the reading of a particular word can make all the difference to its significance. Similar considerations attach to the role and context of the words in the narrative. This is a matter to which we shall return later.

\section{Instrumental uses of the arts}

The foregoing reservation does not rule out the instrumental use of literature, contrary to the second account of the matter outlined above. The novelist or poet can fire the imagination of the reader by suggesting new possibilities and understandings, which the limited experience of emerging and even experienced clinical practitioners precludes. No practitioner's experience is unlimited 
and such limitations might blind him to possibilities which are facilitated by the experience of others. The poet, for example, by use of his gift might open our eyes to realms of experience otherwise closed to us. We might see these for ourselves in his poem or we might be brought to see them by means of sensitive readings and expositions of the poem by others. This growth in imagination can profoundly affect the practitioner's understanding of the experience of his patients and influence his perception of their needs and of suitable interventions. Such an enlargement of the understanding of the life of an Alzheimer's sufferer is afforded by a reading of Philip Larkin's poem, The Old Fools. ${ }^{6}$ The poet's pathological fear of growing old and of death, together with his mother's affliction, informs his powerful portrayal of the horror of the degenerative disease. Yet it also succeeds in getting inside the head of the sufferer and portrays a significant world which obliges the reader to reassess the question of what is a worthwhile life. Whilst such reassessment does not necessitate any particular principle of behaviour or policy of care it does at the very least demand justifications for discounting features of the experience of the patient which might otherwise have been overlooked.

Larkin imagines for us an experience which, whilst inaccessible to others, is none the less in some sense real for the sufferer. But the imagination need not be limited to the actual experiences of anyone, living or dead. The work of the novelist and poet might be employed to open up imaginary realms beyond experience and, once again, to call the reader to reflect upon assumptions and practices which might otherwise appear secure. Whilst the artist creates fictions, even fictions which could not conceivably be realised in fact, it does not follow that they have no bearing on the realities with which we have to deal.

"'But the fairy tale only invents what is not the case: it does not talk nonsense'.-It is not as simple as that. Is it false or nonsensical to say that a pot talks? Have we a clear picture of the circumstances in which we should say of a pot that it talked? (Even a nonsense-poem is not nonsense in the same way as the babbling of a child.)"7

Thus for instance, Louis MacNeice's poem, Prayer Before Birth, puts words into the mouth-per impossibile - of the unborn child, which draw our attention to possible responsibilities which the living might have towards those not yet part of their company. In one sense the poem cannot be said to be true (indeed can any poem be so described?) in that it is not so much a question of how we could possibly detect the wishes of such a prospective person as of how it could make sense to ascribe wishes of this kind. Nevertheless reflection on the poem can be a means of reflecting upon the responsibilities which devolve upon the living to protect the unborn from threats and harms which are both predictable and avoidable. Such reflection is particularly called for among those who play a causal role in facilitating conception and parent- hood by medical assistance. The poem might well be employed to achieve precisely this kind of attention. ${ }^{8}$ In so far as this is so then it is an instrumental use of the work.

\section{Facilitating reflective practice}

The instrumental uses of literature outlined above have something important in common. Literature is not used in either case to support or establish a given line of practice. In that sense the use of it differs markedly from the first account of the use of the humanities in medical education, which is thereby seen at least to be too narrow. Protagonists for the second account might well latch on to this criticism and add that the instrumental use outlined would be most unlikely to effect any change in practice because it would encourage the wrong kind of engagement with the narrative - an engagement rather more akin to that found in proof reading or editing than to that found in the enjoyment of a novel. In so far as this is true then the imagination of the practitioner would be left almost untouched by the exercise.

On the other hand, the outcome for the learner is more predictable than that facilitated by the second account. According to that account the outcome of engagement with the novel would be entirely unpredictable. Consequently the idea of using the literature in an instrumental capacity appears threatened by the breaking of the link between teaching materials and specified "learning outcomes". In both the examples cited above, however, the aim of the employment of the poems was to inculcate a habit of reflective practice. Whilst such a habit does not guarantee a common outcome in terms of the treatment decisions and perceptions of clinicians it does, nevertheless, make a difference to their practice. Moreover it is a difference which could not be of negative value.

In order to give some flesh to this skeletal account of an instrumental use of the arts in medical education, I propose to consider the episode with which this paper began.

The activity of breaking bad news is commonplace in the delivery of health care. It might be the announcement of a death but it is more likely to be the pronouncement of a serious diagnosis or a pessimistic or hopeless prognosis. Whatever the nature of the news its delivery is something for which candidates for the health care professions should be prepared. But how is this best done? Teachers might feel uneasy at simply presenting students either with a list of rights vested in the recipient of the news - the right to know, the right to dignity and respect, the right to be protected from unnecessary harm, the right to fairness and so on or with a list of duties the doctor has to respect these rights. Though each of these might be relevant to the activity, acknowledgement of them might fall far short of good care. Indeed unreflective application of any or all of them might produce the most undesirable consultations with dreadful sequelae.

How can consideration of the Dickens narrative offer a better approach? In so far as it does we can 
ask how it might do so. In line with the two examples mentioned in the last section, the answer will be that study of the narrative can stimulate and extend the imagination in ways which can be productive of better practice, practice which is reflective and perhaps more responsible (though, dependent as it is upon the individual's motivation and values, this further gain cannot be assumed). It is true that such practice might exemplify the values and even principles embedded in rights statements on the one hand and that it might denote an awareness of the self gained from engagement with the novel on the other hand. But, more significantly, the better practice can be attributed in part to the activity of the teacher who employs literature instrumentally to instil habits of reflection in the student, habits which will later inform the behaviour of the practicising doctor. The teacher does not tell the student what should be learned from the narrative, poem or painting so much as teach the student how to engage with the piece in a way that will be relevant to practice contexts. This might involve enabling the student to ask significant questions, recognise wider ranges of possibilities, acknowledge personal traits and so on.

To illustrate how this might be possible let us compare Dickens's narrative of the bad news encounter with that of the $1999 \mathrm{BBC}$ dramatisation of the novel. The dramatisation took some liberties with Dickens's text. The changes were neither accidental nor necessitated by virtue of the constraints upon the production to condense the content of the novel into a reasonable length. Nevertheless they might be seen as demanded by the need to distil the essence of the story into a manageable timespan. A comparison of this sort facilitates the identification of important issues which need to be taken into account when attempting to develop good practice in breaking bad news. It also illuminates those issues and stretches our imagination with respect to the development of practice policies.

\section{Setting the scene}

According to the BBC account the episode occurred in the schoolroom of Salem House, before the headmaster's desk. David could barely see over the top of the desk, behind which sat the towering figure of the headmaster himself. The child had been made to suffer in this room before. Here he had suffered his first cuts from the cane which now sat ominously between him and $\mathrm{Mr}$ Creakle. He remembered that occasion, when consent had not been sought but when, nevertheless, full information had been divulged:

"He told me that if I were famous for biting, he was famous for biting too. He then showed me the cane, and asked me what I thought of that for a tooth? Was it a sharp tooth, hey? Had it a deep prong, hey? Did it bite, hey? Did it bite? At every question he gave me a fleshy cut with it that made me writhe: . . . and I . . .was very soon in tears."

Every waking moment in that institution the boy's eye was alert to the presence of this authority figure whose guest he was. Salem House was anything but a haven of peace. It promised continually a menu of pain, suffering and fear. And here he stood at the focus of all that, without physical support, alone, to hear the awful truth.

Contrast this setting with that provided by Dickens. David is invited to the parlour, the comfortable, homely setting of the Creakle family. He is led to the sofa and Mrs Creakle sits beside him. The threatening figure of $\mathrm{Mr}$ Creakle, his cane ever before him, lurks in the background as a dark presence, but the parlour is a world away from the schoolroom. A mirror hangs upon the wall into which the child looks later to see how red his eyes had become due to his crying.

The sense of tragic suffering and injustice endured by Copperfield is heightened by the BBC setting, which compounds the isolation and vulnerability felt naturally by recipients of such news. The translation of this intriguing juxtaposition of settings to the medical world is not difficult to make. The more humane the context of the sharing of bad news can be made the better it will be. For those working in hospitals there is little sense of threat or foreboding attaching to the institution. They are clearly places of healing where experts with authority to deal with health problems dedicate themselves to the care of their patients. To many patients the hospital appears a very different place. For them it might signify nothing but the threat of disease, the prospect of pain and death and the terrors of clinical intervention. Whether bad news is best shared there or elsewhere, such as in the patient's home, is a question worth asking.

The possibility of moving outside the hospital setting might be all too slim in many cases where the patient cannot be transferred in the short term, the home is remote from the hospital, or the health professionals cannot accommodate domiciliary visits in their busy programmes and so on. But in such cases we need to ask whether all settings within the hospital are equally suitable. One of the telling features of the Dickens setting was that the child could be left alone for short periods once the news had been shared. He was allowed to remain there throughout the day, protected from the uncaring bustle and pressures of the life of the school and from prying or uncaring eyes. In the television adaptation his space could have been invaded at any moment by a horde of noisy schoolboys amused, embarrassed or simply untouched by his plight. People generally wish for solitude when trying to absorb or come to terms with devastating news. It ensures privacy as they express their initial shock, grief or relief or whatever combination of these might occur. This might be done alone or with loved ones but out of the gaze of the agents of care, the messengers of the bad news, strangers, helpful though they might have been. There is little opportunity for this in a busy clinic, or in an open ward where a curtain at best might protect the recipients from the attention of further strangers.

Whatever the constraints, reflection on the setting of the encounter is called for. 


\section{Identifying the message with the messenger}

When we think of what is to be said, in the sharing of bad news, it is tempting to concentrate upon the words. But this is to miss much that determines the content of the narrative, the significance of the communication. There is little to choose between the Dickens text and the BBC production of the story with respect to the dialogue. The dramatic production remains faithful to most of the words written by the author. But the significance of those words is greatly altered by the choice of their mouthpiece. As surely as it is the case that change in the intonation of a word can alter its meaning, as noted earlier, so too can the identity of the speaker.

"Copperfield to report to Mr Creakle", cried Tungay, the loathsome wooden-legged headmaster's lackey. The command struck fear into the child's heart. Creakle was not a caring soul. Indeed he was a sadistic bully. His dedication to cutting with the cane was almost a matter of professional pride as David noted: "I should think there never can have been a man who enjoyed his profession more than $\mathrm{Mr}$ Creakle did. He had a delight in cutting at the boys, which was like the satisfaction of a craving appetite. I am confident that he could not resist a chubby boy, especially; that there was a fascination in such a subject, which made him restless in his mind, until he had scored and marked him for the day. I was chubby myself, and I ought to know." 10

The words which fall from his lips, between mouthfuls of breakfast toast, take on an even more sinister turn, therefore, than they need have done. Following the general excursis on learning about peoples' passing away there follows the progressive torture from the question, "When you came away from home at the end of the vacation, were they all well?" through the rest. Each succeeding inquiry and statement seems calculated to tighten the screw on the poor pupil's emotions with which the headmaster plays like a cat with a mouse. Was your Mother (as opposed to Dickens's "Mama") well?-I grieve to tell you that she is very ill.- She is very dangerously ill.- She is dead. The episode impresses the viewer as a piece of black humour, a sick joke, and, moreover, one designed to cut the child's feelings as surely as the cane had often cut his flesh.

In the Dickens text a kindly schoolmaster invites the boy, using his first name, to the Creakle's parlour. On arrival he is met by Mrs Creakle, who proceeds to handle the delicate matter of communicating the terrible news. Her manner is warm and friendly. Her tactful acknowledgement of his youthfulness and the inevitability of death serves as an important preparation for what is to follow. We are helped to understand the impact of each stage of the conversation by the child's own commentary. Already he appreciates that something serious is to come as he looks at her earnestly. The mention of his mother and the inquiry after her health focuses his attention even further, causing him to tremble though he did not quite know why. Mr Creakle, who allowed his wife to handle the delicate matter, had little sympathy with the pussy-footing approach. "He shook his head without looking at me and stopped up a sigh with a very large piece of buttered toast." 10

The step by step approximation to the awful truth further prepares the child for the worst. So much so that once he hears that Mama is dangerously ill he stumbles upon the whole matter for himself. "I knew all now. She is dead. There was no need to tell me so. I had already broken out into a desolate cry, and felt like an orphan in the wide world." 11

We do not need to assume that the approach was sensitive for David tells the reader that Mrs Creakle was very kind to him. The truth had certainly dawned upon the lad, which is far from what is often reported to have happened when bad news is shared in the medical setting. ${ }^{12}$

The author recalls a postgraduate student, a senior nurse who had worked for many years on a paediatric ward with two consultants, describing her colleagues' widely different approaches to sharing a poor prognosis with parents. The one, a brilliant diagnostician, regularly told the truth as it was, baldly and with the maximum economy of words. This direct approach often caused great distress and ward staff were left to pick up the pieces. Moreover the parents often needed to be faced again with the truth on later occasions, having failed either to register or come to terms with it and all the consequences of their initial encounter with the clinician. This model of breaking bad news has been dubbed the "full disclosure model" and has been described as paternalistic since it takes no account of the patient's desires about the timing and amount of information disclosed. ${ }^{13}$ His colleague took consultation with the parents more seriously. A number of meetings would occur. At the first the various possible diagnoses and prognoses would be canvassed and written information shared. At the second meeting the feelings of the parents would be explored. How were they coping with the possibilities? How did they find their child was coping with his or her problems? Did they have any further questions to ask? At the third meeting the doctor would ask the parents what they thought was the most likely outcome of treatment. Invariably they produced the prognosis which the doctor agreed with. But it was a truth for which they had been prepared and to which they had come with careful assistance-rather like Copperfield in the Dickens story. This partnership model of breaking bad news has been identified in the literature. It involves negotiation, the development of trust and dedicated time. ${ }^{14}$ It would be unwise to lay down a protocol for this activity or even guidelines, given the degree of variation between cases. Breaking bad news according to protocols would be rather like painting by numbers, the results would lack precisely what is called for in each activity, namely sensitivity to the meaning of what one is doing. Nevertheless, the duty to consider carefully the when and how of sharing bad 
news is incumbent on health care practitioners, and use of the arts can be of assistance in this regard.

\section{Choosing the messenger}

We have identified the relevance of the identity of the speaker with respect to the significance of the words spoken during such encounters. But how should we go about choosing the messenger? Once again consideration of the Dickens tale, while not giving us an answer, will assist us in getting cleare about what is at stake in relation to the various possibilities.

We must not forget what we have already observed in deciding who is best placed to share the news. On the other hand, in many medical contexts it is the person with authority, the person with the most thorough knowledge of the information to be shared who is, at least from that point of view, best placed to perform the task. This might well be why, in some studies, doctors have been found to be the preferred sources of such news by many patients. ${ }^{15}$ On the other hand there will be occasions when others will be as well informed and perhaps better placed to serve. David's image of $\mathrm{Mr}$ Creakle disqualified the headmaster from being an ideal candidate for the disclosure of his mother's death. The professional dedication to cutting boys got in the way of his caring for this boy. One would hope that no surgeon's practice could be described in the terms chosen by David to describe his headmaster's "professionalism". Yet, there is no doubt that the temptation to see patients as interesting cases, as opportunities to pursue research or to innovate, or simply as further ciphers on the managerial spreadsheet of throughput figures or health gain targets can blind practitioners to the human situations before them. There is no easy escape from this problem. To combine adequate knowledge and proper sensitivity can be problematic. Even if alternative health carers are called in to help, the patients will know that there might be, in the last analysis, a conflict of loyalties, as surely as there was for Mrs. Creakle, who herself stood in a relation of fear to her husband. All the possibilities for improving this facet of patient care need to be considered, however, because many practitioners have personal problems in tackling bad news. Among these might be the fear that such news might betray their failure to live up to the miracle-working myth of modern medicine. Certainly numbers of practitioners have been aware of their lack of training in communication skills in this area of care ${ }^{16}$ Whilst medical schools are now more sensitive to these needs than they used to be, problems still exist. Some study of the medical humanities could be useful in addressing these.

\section{Conclusion}

It has been claimed in this paper that the medical humanities might be useful in helping to address some of the difficulties which doctors have in a particular facet of their work. The claim has been based on an attempt to show how the instrumental use of a comparison between an author's text and its dramatisation might illuminate a problematic area of practice. Such activity, it has been claimed, takes the literature seriously in that it enables students who engage with the text to reflect upon their behaviour. This engagement does not promise solutions to problems of practice in the form of rules of action. Nevertheless it does inculcate a habit of reflection which can enlarge the imagination of practitioners and thus inform their practice.

Donald Evans is Director of the Bioethics Research Centre at the University of Otago, Dunedin, New Zealand.

\section{References}

1 Dickens C. The personal history of David Copperfield [vol 1, the London ed]. London: Caxton: 92-3

2 Gillon R. Imagination, literature, medical ethics and medical practice. Fournal of Medical Ethics 1997;23:3-4

3 Prickering N. Imaginary restrictions. Fournal of Medical Ethics 1998;24:171-5.

4 Holy Bible. 2 Samuel 12

4 Holy Bible. 2 Samuel 12. $214 \mathrm{e}$.

6 Evans D. Values in medicine: what are we really doing to our patients? [inaugural lecture]. Dunedin: University of Otago, 1998: 59-65

7 See reference 5: para 282

8 Evans D. The interests of the child in medically assisted surrogacy. The International Family Law. December, 2000:167-72.

9 See reference 1: 67

10 See reference 1: 92

11 See reference 1:93.

12 Bertakis KD. The communication of information from physician to patient: a method for increasing patient retention and satisfaction. Fournal of Family Practice 1977;5:217-22.

13 Girgis A, Sanson-Fisher RW. Breaking bad news: consensus guidelines for medical practitioners. Fournal of Clinical Oncology 1995;13:2449-56.

14 Donovan K. Breaking bad news, In: Sanson-Fisher R, ed. Interactional skills: doctor/patient relationship. Newcastle, Australia: University of Newcastle, 1990 and Matthews E. Can paternalism be modernized? fournal of Clinical Oncology 1986; paternalism

15 Levenson PM, Pfefferbaum B, Silberberg Y, et al. Sources of information about cancer as perceived by adolescent patients, parents and physicians. Patient Counsel Health Education 1981; 3:71-6.

16 Parkes CM. Communication and cancer-a social psychiatrist's viewpoint. Social Science and Medicine 1974;8:189-90. 